\title{
LUMPERS, SPLITTERS AND SAGGING PILLARS
}

\author{
Hal B. Levine \\ with contributions from \\ Paula Brown Glick
}

\begin{abstract}
Anthropologists have been narrowing the scope of the discipline for a long time. It has become less comparative, less concerned with wide-ranging questions about human nature, more narrowly ethnographic and increasingly relativistic. These trends have become strong enough in recent times to seriously undermine anthropology's fundamental project - to understand social and cultural reality. Personal experiences with researching and writing about ethnicity, kinship, and questions of social scale are chronicled here in a paper that supports the need to move beyond ethnography in order to productively confront important issues. The section on scale contains contributions by Professor Paula Brown Glick, the well-known ethnographer of the Chimbu, who has recently received recognition of her lifetime achievements by the Association of Social Anthropologists of Oceania.
\end{abstract}

Is moving 'Beyond Ethnography' (the theme of the 2005 ASAANZ conference) a good idea? Kapferer (2000) says anthropologists have been attempting to do this for some time and it's hardly a welcome development. Ethnography is one of what he calls the 'two pillars' of social and cultural anthropology. Undermine it and the whole house may come down.

The second pillar is culture, and, as we all know, this one's under critical scrutiny too, (see Brumann 1999 for a comprehensive review). Personally, I (HL) find the issues about culture more engaging than the tribulations of ethnography, but, of course, they are closely inter-twined. Ethnography, as a method, is designed to get at culture; ethnographies, as texts, are designed to portray cultures. The dance between the two seems to move in ever-tighter circles. 
And that's because, to continue speaking of pillars, the third, comparison (see Sanjek 1996 and Durrenberger 1996), has already slid into the chasm where culture and ethnography are poised. Without comparison we produce a corpus of vaguely connected relativistic texts.

I have often confronted the limitations of the continually narrowing horizons of our discipline in my own research work. This paper presents a concrete, experience-based case for reversing the trend. Going beyond ethnography can work well if it's done in the spirit of reinforcing (rather than deconstructing) the tripartite project of anthropology.

ETHNICITY, SURROGATE MOTHERHOOD AND BIG MEN

Ethnicity is a concept that I've been concerned with since the 1970's. I decided to state my final position on its nature in a paper published in 1999. I argued there (Levine 1999) that the ethnicity literature is stuck in a rut, endlessly recycling primordial and situational theories with an occasional foray into psychoanalytical explanations that hardly help to give the concept any traction. The solution I saw was to move beyond the view that ethnicity is only, or even mainly, a cultural thing and to start considering cognition. Certain features of categorization are part (dare I say?) of human nature and need to be integrated into explorations of social, cultural and historical events to understand this complex phenomenon. Furthermore, the concept itself refers to something real - categorizing people in terms of their origin. It is not, as Banks (1996) eloquently argued, something that exists, not in the world but in the minds of anthropologists and our fellow travelers.

I made a similar argument in regard to kinship (2003). Once a central focus of social and cultural anthropology, fundamentally comparative with in-built considerations of biology, folk biology, categorization, social organization and culture, kinship was deconstructed by Needham (1971) and Schneider (1968) long before most of us even knew what the word deconstruction meant. Kinship ceased to exist as a thing in itself and became conceived of as something that operates in cultural realms of gender, power, difference, contradictions, paradox and ambivalence (Peletz 1999). Embedding kinship in this way discourages broad comparison. However, the advent of gestational surrogacy and other technological interventions in human reproduction rekindled anthropological interest in kinship. Questions very similar to those that were dropped twenty-five years previously by anthropologists started to be raised in newspapers, the courts and the internet. 
Robin Fox, for example, became a participant in a famous surrogacy trial that took place in the state of New Jersey, where he was a professor. The surrogate mother had signed an agreement stating that she would give her baby, conceived with her egg and the contractor's sperm, to the man and his wife. However, she changed her mind and was taken to court to enforce the contract. Fox, the social anthropologist who has best resisted the general turn away from biology, especially in regard to kinship, argued that the deal was unenforceable because as a mammal, the surrogate unavoidably bonded to the fetus. The courts were waging, he said, the latest round in a battle that has been going on for thousands of years between status and contract as organising principles of society and contract seems to be winning. Indeed, custody of the child was granted to the father and his wife although the surrogate was awarded visitation rights on appeal.

Marilyn Strathern (1994) argued, in a review, that it's not a case of the natural bonds of kinship losing out to law. Surrogacy has stimulated more of both nature and culture. The courts are concerned with how people become mothers and fathers as well as the contractual rights of the various parties to surrogacy agreements. This seems a valid point from reading both the legal literature on surrogacy and writings of anthropologists interested in the law. Strathern is well known for her point that kinship is 'the site for producing what will count as the difference between nature and culture' (Franklin and McKinnon 2001, $26,20)$. She and other anthropologists who write about reproductive technology, 'talk of the implosion or collapse of nature and culture...all concepts of nature...are already shaped... with the imprimatur of culture.' (Thompson 2001:198).

This culturalisation of nature conflates, rather than unifies the two realms. Women become surrogates because they want to help infertile couples, earn money at home while caring for their own children, and enjoy being pregnant. The first two motives, clearly social and cultural, are well accounted for, especially by Ragone $(1994,1996)$ who, citing Schneider's work on American kinship, emphasises that the ideology of surrogacy represents it as culturally appropriate. The women are creating motherhood and fatherhood for another couple by giving them the gift of a child. The third motive is mentioned but not given any attention. When I looked into a website for gestational surrogacy (the surrogate is impregnated by donor embryos and shares no genes with the fetus) I found that the women who become surrogates did indeed talk about giving the gift of life and downplayed the inconsistencies between their traditional roles as wives and mothers and their newfound public personae as surrogates. It was, however, also apparent that they have strong personal desires 
to give this particular gift. The creation of an ideological regime of surrogate motherhood proceeds by an alignment of desire, emotion, personal choice and cultural values in interesting and efficient ways. I suggested in my paper that surrogacy disrupts the elements of our kinship system enough to show that they do, like ethnicity, exist outside the imaginations of anthropologists. Reducing kinship to culture, by making nature cultural, takes our eye off the ball. A more productive question to ask is how do biological, psychological, social and cultural elements come together to create kinship?

These two examples indicate my own ideas about moving against centrifugal tendencies, tighter and tighter circles, chasing tails, and how we might prop the wobbling pillars by widening our perspectives. In the rest of this paper, I want like focus on a more recent situation that I mentioned briefly at the conference in Wellington.

Paula Brown Glick, an anthropologist recently honoured by the Association of Social Anthropologists of Oceania for her long-term ethnographic research on the Chimbu, asked me to participate in an ASAO Informal Session, entitled Scale and Complexity in Melanesia. This session was organised to explore the issue of why most indigenous societies of Melanesia lack hierarchy. The region was an early center of plant domestication and contains some of anthropology's best-known examples of trade and exchange systems, ritual practices and cults. Yet Melanesian big-men amass little wealth or power and do not establish stable hereditary polities.

What I found most interesting about the problem was that it seemed a specific instance of questions that had recently become topical due to the influence of Jared Diamond's Guns Germs and Steel and his new book Collapse (2005). In the course of his wider exploration of the reasons for western world domination, Diamond (1996:99) specifically discusses the constraints on hierarchy that existed in the New Guinea highlands. It was there that the densest populations of Melanesia are found. However, the area of land that could be effectively planted and settled was small, limited by altitude and geological fragmentation. The population remained far smaller than that of any other area of independent domestication in the world. Locally grown root crops were low in protein. No suitable mammals existed that could be domesticated and used for traction or transportation. Mountains and seas restricted possibilities of technological and socio-cultural interchange with other regions. The local population was very fragmented, linguistically, socially and culturally, and by frequent warfare. 
When I emphasized the significance of Diamond's environmental explanation to our session in Hawaii the other participants were skeptical. They were particularly dubious about the lack of an autonomous role for culture or human agency in Diamond's account of the processes that stimulate the development of different social systems. The Melanesian emphasis on egalitarianism, a rejection of hierarchy, concerns with controlling ritual rather than achieving secular power, and the tendency of men to dominate women and not each other, are cultural factors that were posited to have kept Melanesian societies egalitarian and small in scale. The influence of Austronesian speaking people, the arrival of sweet potatoes and the existence of some chiefly societies in Melanesia seemed to rule out simple environmental explanations for Melanesian egalitarianism.

However, it seems to me that the scope of the issue is curtailed radically if we ignore Diamond, or at least the factors he mentions, and stick exclusively to considering society and culture in Melanesia. Using Diamond doesn't require us to disregard or downplay culture and human nature, especially since a perfectly good social and cultural anthropological version of Diamond can be found in the work of John Bodley. The issue boils down to what, in biological anthropology, would be termed a debate between lumpers and splitters. Being a lumper, I favour explanations like Diamond's that are broad, scientific generalizations. Splitters prefer local context, thick description and meticulous detail. Sure, we need both, but generally speaking, the splitters have the lumpers on the ropes. Exploring the different views that Paula Brown Glick and I have about what goes into producing scale and complexity highlights the importance of moving beyond wherever it is we are now.

FORMULATING A QUESTION ABOUT MELANESIAN BIG MEN (PBG)

I (PBG) have been thinking and writing about political questions, power, authority, political organizations for, I think, all of my career in anthropology, beginning with field research in Red Lake Indian Reservation and a master's thesis in Chicago, going on to a Ph.D. (London) on West Africa and now for many years on Melanesia and the Chimbu (e.g. 1960, 1990). The key questions remain. Is there an evolutionary process that leads from bands to states? Do the many systems past and present line up as a continuum?

The political anthropology writings continue to assume that political systems evolve. Historically, once the food supply is controlled, social scale and complexity increase. Anthropological theory holds to the neo-evolutionary series of band - segmentary tribe - chieftainship - state. Society develops hierarchy, stratification, inherited status, inequality, hereditary power, authoritative rule, 
legal sanctions, tribute, conquest, incorporation. This paradigm, traceable to Durkheim, Radcliffe-Brown, and the contributors and editors of African Political Systems (Fortes and Evans-Pritchard 1940), persists in the writings of many anthropologists, especially those writing of developing states. I think that in Melanesia we may find a good example of a corpus of ethnographic data that does not support the evolution of political forms. The variations of political structure do not line up as a continuum. Great men do not become bigmen, nor do bigmen systems evolve into chiefdoms.

Some of the relevant questions to explore are: Are ritual powers inherited? What is the pattern of succession to political power? How are sanctions applied? What is order? How is authority applied? What are the powers of a leader? That is, we may discuss political systems in typological fashion, but, do they show evolution? For any one community or people, what can we say about the characteristics of the system, power, and action?

Our focus on the evolution of complex political systems remains linked to the differences within the Pacific area. Some Pacific islands, especially Hawaii, Tahiti, Tonga, Fiji developed states, rulers, hereditary privilege while Melanesians did not. Samoa and New Zealand had local hierarchy without states and a few Micronesian and Melanesian societies (e.g. in the Solomons, the Trobriands, Mekeo) had hereditary ritual leaders, so there is convergence as well as difference. But, the vast majority of groups in mainland New Guinea and some of the islands were non-hierarchical, competitive, with big men or great men. War, trade, exchange festivals, and local group and individual competition were important activities, but unlike elsewhere, they did not lead to conquest or domination. Our question is why not?

We know that Melanesia and New Guinea have had agriculture for thousands of years. But the evolutionary sequence did not happen. Small communities continue. There is no accumulation of wealth or property. Rather, trade, exchange, achieved short term leadership of big men, competitive relations between men and between communities is usual. There is no political centralization. There are a few cases of kinds of hereditary chieftainship, special knowledge of magical spells, sorcery techniques which apply to all the community, but not much beyond. The chiefs have hereditary status as ritual leaders, but this is not power and control. Polygyny and attraction of followers gave some big men an ability to raise many pigs and attract valuables, bringing esteem, but this does not establish political power or hereditary status. 
GUNS, GERMS AND STEEL

I (HL) wonder if Paula's question about why we find these different forms of political centralization and whether they form an evolutionary sequence really requires re-engaging with the great ethnographic corpus of questions, case studies and topics she specifies. Certainly, if we want to know how hierarchy fails and egalitarianism works in Melanesia we need to go into all of this. Indeed, the strength of ethnography is its ability to elucidate how society and culture work. The question here is a 'why?', and ethnography is particularly weak in addressing 'why' questions. It seemed obvious to me that Diamond provides most of the answer (as mentioned above) to why Melanesian leadership remained non-hierarchical. The dozen participants at the ASAO session appeared unimpressed.

(PBG) Surely there are multiple causes for differences in world conditions. Diamond maintains the Service evolutionary paradigm of band, tribe, chieftainship, state, and poses Yali's question in relation to that. His ultimate causes are mainly geographic and environmental, beginning with food production and sedentary communities, going on to competition and diffusion, food storage, population density, epidemics due to spread of animal diseases, large animal domestication and power, political centralization, stratification, hereditary offices, conquest and domination. All this a western-based evolutionary sequence that underplays culture, values, individual invention and trade. It's impersonal, without agents.

Yali's Question (which Diamond poses rhetorically as his task to answer in Guns Germs \& Steel) is 'Why do Papua New Guineams lack cargo'? Why is it that Europeans have so much more wealth and power? Errington and Gewertz (2004) see Yali's question differently. For them he is talking about respect, objecting to the white man's condescension, rather than desiring their goods. Their book on Ramu Sugar (2004) is very interesting and shows how PNG people use their wealth for personal and social dispersions, not improved housing or investment. A nice study but not very pertinent to our question.

I (HL) agree that their book isn't useful to questions of scale but Errington and Gewertz's spin on Diamond provides a wonderfully clear example of anthropological boundary marking that is very significant to the situation at issue here. It's a specific instance of what Goldblatt (2006) calls 'Academia's Version of the Tower of Babel'. His essay is entitled 'Can Humanists Talk to Postmodernists?' This is a wider cast to the question of this paper. Not so much, 'Why is there no hierarchy in Melanesia?' or 'What did Yali really mean?' but, 'How, and to 
whom, can humanist anthropologists talk about these things?' Here is what Goldblatt says about engaging with postmodernists.

By a 'humanist,' I mean a person who believes that human beings can formulate true or false opinions about a reality that exists independently of their thoughts and language - and that the truth or falsehood of such opinions is gauged by their correspondence with empirical evidence analyzed in light of fundamental rational principles. By a 'postmodernist,' I mean a person who believes that the perception of a reality existing independently of thought and language is illusory, that what the humanist perceives as reality is in fact a linguistic construct of the phenomena of subjective experience that is continually adjusted in response to a fluid social consensus. Finally, by 'talk' I mean to put forward opinions, or sets of opinions, in such a way that they may be either verified or falsified. Of the two possibilities, verification and falsification, I would lay particular emphasis on falsification since it is less provisional. (Falsification, in other words, is less contingent on evidentiary standards. For example, it only takes one black dove to falsify the proposition 'All doves are white'; whereas, the standards of support required to verify the proposition inevitably vary.) To talk, by my definition, is to risk one's continued avowal of an intellectual position, to enter willingly into the so-called 'marketplace of ideas' in which logical demonstration is recognized as the final arbiter between opposing viewpoints. My thesis, then, is that no such marketplace of ideas can ever truly exist between humanists and postmodernists because postmodernists neither pursue verification nor risk falsification in their exchanges'.

Errington and Gewertz held forth about Diamond on the weblog, 'Savage Minds. Their comments and one of the replies clearly resonate with the Goldblatt quote.

Diamond...misunderstands what many P New Guineans desired when he explains the background to Yali's question (about the differences between white and black people). In Diamond's words: 'whites had arrived, imposed centralized government, and brought material goods whose value New Guineans instantly recognized, ranging from steel axes, matches, and medicines to clothing, soft drinks, and umbrellas. In New Guinea all these goods were referred to collectively as 'cargo' (1999:14). Because Diamond misunderstands that Yali really was asking less about cargo per se than about colonial 
relationships between white and black people, he describes the introduction of centralized government as almost parenthetical to the indisputable fact that whites and their goods had arrived. Thus, he presents local resentment as directed not at the nature and use of concerted colonial power so much as at the differential access to goods.

Gewertz and Errington do something incredible here that prompts lawyers (at least on TV) to shout in objection 'asked and answered'. This is when an attorney asks a witness a question and then answers it herself. Actually, it's even worse. It's misrepresenting the witness in a way that totally sidetracks the discussion. In fact, Yali actually spoke to Diamond and said 'Why is it that you white people developed so much cargo and brought it to New Guinea, but we black people had little cargo of our own?' It's a real question from when they met on a beach in 1972. They talked for an hour (Diamond 1998:13-15). Where's the evidence that Yali meant something other than what Diamond reports? How can we expect Diamond's ideas to be evaluated fairly by such a strategy? I suppose a postmodernist might reply to the effect that nobody can tell what anyone means by anything and one interpretation of Yali's question is as good as another. We can criticise Diamond by deconstructing his position as a privileged white academic. But wait, aren't Errington, Gewertz and Diamond (and $\mathrm{HL}$ ) all privileged white academics? And am I doing to Gewertz and Errington what they did to Diamond? No, I'm not! First, let's hear more from them.

Pizarro, Millais, Diamond, and Yali: Our Last Waltz.

Posted by Fred and Deborah under Uncategrized, Culture Notes, Pacific, Race, Political Economy.

The anthropological view of history we present in Yali's Question is crucially unlike Diamond's in its emphasis on what needs to be taken into account. Diamond, less by default than by design, denies significance to cultural differences - to particular, historically located visions of the desirable and the feasible.

How, then, might we respond to Yali's question? Why did white people deny equality and full humanity to black people? Our full response would be more proximate, more complex, and more messy than Diamond's. It would consider, as essential background, the rhetorics, practices, contingencies, and exigencies of 19th and 2oth century global expansionism. Such a consideration would involve, 
among other matters, the often contesting perspectives concerning how human beings might legitimately derive profit through the use of others, at home and abroad: whether used as slaves, indentured laborers, piece workers, or wage earners. It would also consider, as we have done in our book about one PNG sugar plantation, the often contesting perspectives concerning what might be done for Yali and others to achieve worth in an independent PNG. Although our book is only a partial answer to Yali's question, and one addressed more to the several generations that have followed Yali than to Yali himself, it is, we think, an example of the form any answer should take. It is the kind of answer that anthropologists (and many historians) do provide in its willingness to listen seriously to others and scrutinize their own taken-for-granted understandings.

It is the kind of answer that reveals the differences between the necessary and sufficient causes of historical phenomena - that insists that people who have the power to dominate others in faraway places do not automatically find it desirable to do so. It is the kind of answer that shows colonial expansionism and domination to be the product of the historical and cultural circumstances of capitalism, rather than the product of the inevitable workings of human nature. Moreover, it is the kind of answer that shows capitalism (as well as expansionism and domination) as often justified through narratives about human nature - narratives like Diamond's of the seemingly inexorable.

This kind of answer would also be appropriate to the question of what Yali and the other P New Guineans might do if they were long the ones with significant power - if various historical shoes had been, as it were, on other feet. In fact, we are often asked by students whether Yali, with such guns, germs, and steel on his side, would have acted as a Pizarro. Our response must be that it all depends on what conditions - on what contexts - are assumed. If Yali was the product of the sort of history that produced the concentrations of power that made Pizarro's conquest feasible, Yali would not be Yali. Under such conditions, he might be Pizarro - or he might be de Las Casas. On the other hand, if Yali and the other P New Guineauineans who feature in our story were the products of the history they actually had, we venture that (at the very least) they would be reluctant to leave kin for lives of reckless and ruthless conquest on behalf of the likes of God, King, and gold. Their preferred world, 
while doubtless still of assertiveness and contention, would, we think, be one of maximized entailments rather than of maximized annihilations.

It is, as we have said, that people not only make war, but also make peace; they not only employ techniques and technologies, but also think about how these should, or should not, be used. And they not only pursue outcomes, but also evaluate outcomes. To understand all of this - to understand how history happens - requires attentive listening. It requires conversations that probe and interrogate the range of perspectives held by culturally and historically located actors, ourselves included.

Gewertz and Errington seemed to have things their way on Savage Minds until;

September 12th, 2005 at 9:19 am Patrick says:

Ok, some stuff I don't understand.

1. Why do you keep misinterpreting Diamond's 'inevitability?' As I've written before, Diamond's 'inevitability' is the sort of inevitability one refers to when claiming that a wide proliferation of handguns makes a few murders 'inevitable.' It's one that says, human nature being what it is, when the means are available to a great number of independent actors, at least some will make use of them.

2. Why is making that sort of argument a denial of culpability on behalf of the people involved? Diamond isn't saying that human beings are automatons. He's saying that, deep down, a lot of them are kind of jerks. And given the ability to conquer, at least some will. And it only takes a handful when the power differential is as high as it was. How does this excuse those cultures which actually do it? Using the handgun example above, would you claim that someone who explains a high murder rate in terms of easy access to lethal weaponry was 'excusing' the people who chose to pull the trigger? It seems obvious that both positions can exist alongside one another.

3. A related issue - why can't people see that there can be multiple but-for causes? There's two here. But-for the decision to conquer, it would not have occurred. But-for the availability of the means to 
conquer, it would not have occurred. Diamond argues that the first was extremely likely to occur in at least one culture with the means, and probably several. He argues that the second was prompted by various historical circumstances that he finds in geography. Why is this a problem? If you mean to attack either of these, you need to actually DO it. Stating merely that its possible to not decide to conquer doesn't work once you realize that Diamond is arguing likelihoods, and concluding that they are extremely high given the numbers involved (in the 'it's inevitable that someone will win the lottery soon, now that it's risen this high and this many tickets are being purchased' sense), not computer-like slavishness to unseen and morally unculpable guiding hands of geography. Merely citing the hypothetical chance that an extremely unlikely event could have occurred does not negate an argument about likelihoods.

Gewertz and Errington came back;

Diamond's view of an inevitable and inexorable course of human history, one driven by the operation of ultimate causes over the span of its 13,000-year course, rests...on an implicit view of human nature...give a guy - any guy - half a chance and he will conquer the world... This implicit view of a trans-historical and trans-cultural human nature is consistent with Diamond's explicit rendering of both historical context and cultural perspective as irrelevant. In fact, Diamond works hard to exclude such perspective and context from his scientific history.

To our position concerning history's rootedness in human culture, rather than in human nature...it follows that human beings have a measure of choice about how to act.

(http://savageminds.org/2005/o9/03/about-yali/\#comments).

Finally! Patrick's comments force something humanistic (in the sense Goldblatt uses that term above), to emerge, a consideration of the relationships between culture and human nature. Gewertz and Errington present it as a clear choice, either human nature or cultural context. Of course, this has to be wrong. Culture and human nature must interact to produce any of the phenomena we are interested in here and anywhere else in anthropology.

Richard Scaglion, (2005) one of the participants in the ASAO session made a 
statement about the development of hierarchy that addresses these questions.

I view 'egalitarian' existence as a relatively normal way to live, and I believe that the real task is to examine how and why hierarchy develops and persists. How do common people get suckered into buying into hierarchical models? In a book that I have often thought was insufficiently appreciated, Guy Swanson (The Birth of the Gods, 1960, U. Michigan Press) established a statistical link between belief in high gods and social hierarchies (or, to look at it the other way around, between egalitarian existence and the absence of belief in high gods). This always made perfect sense to me. Why would egalitarian folks dream up a supernatural that contained social models with which they were not familiar? Especially in early contexts in New Guinea, for example, where everyone was egalitarian, how could people even imagine hierarchy, or situations in which some people had unquestioned power to give orders to others? It makes sense to me that people tend to conceive of a supernatural that models their own social system.

I think that something similar may have gone on with hierarchy, especially in the New Guinea Highlands in the early days.... I discussed the existence of hierarchy among Austronesian groups in Melanesia 'Chiefly Models in Papua New Guinea' in The Contemporary Pacific (8:1-31, 1996) in it I argued that hierarchy, and consequently 'chiefs', have been characteristic of Austronesian-speaking peoples for a very long time. Speakers of languages of the Austronesian language family are found throughout Microneisa and Polynesia, of course. Within Melanesia, Austronesian languages predominate or are exclusively present in Fiji, New Caledonia, Vanuatu and Solomon Islands. By contrast, speakers of non-Austronesian or Papuan languages constitute the overwhelming majority in Papua New Guinea and Irian Jaya. I am sure that you all know that the Austronesian language family is relatively new to the Pacific, at least as compared with the nonAustronesian or Papuan languages, and that there is reasonable archaeological evidence that Austronesians were already hierarchically ordered societies when they entered the Pacific. So my basic answer to Hal's question of 'Why some Pacific islanders and especially Polynesian Hawaii, Tahiti, Tonga, Fiji developed states, rulers, hereditary privilege.... [whereas] ... The vast majority in mainland New Guinea and some of the islands were non hierarchical, competitive, with big men or great men... No conquest or domination.' has to do primarily 
with historical factors. Austronesian societies had already developed hierarchical models in a different cultural context, as complex agriculturalists in a homeland in or near Mainland Asia. In this sense, they arrived in the Pacific with these models already in place, and were able to successfully adapt them in their new homelands. NonAustronesian societies, by contrast, had not developed such models, apparently did not need them.

Scaglion's point that egalitarianism is natural, that it is hierarchy that needs explanation, appears similar to Gewertz and Errington's. However, it is more contextually nuanced and empirically based than their stark choice. John $\mathrm{H}$. Bodley's power-elite hypothesis (1999) gives us a good handle on these particular aspects of the bigman and Yali questions. Like Scaglion, Bodley thinks that people prefer not be exploited. Although not everyone is after power, in any collection of humans some people dominate others. Those who successfully use socioeconomic growth to their advantage become elites with the power to direct social and cultural change and hence the ultimate development of social scale. Bodley says that 'elite-directed cultural evolution has produced distinct domestic-, political-, and commercial-scale cultures' (1999:595). So, Diamond's view that Melanesian groups never moved beyond big-man systems because the resources necessary for the development of larger scale societies did not exist does not violate what we know about human nature or culture. The Austronesians brought their more hierarchical social organisation with them from South-East Asia and adapted it to local realities in the course of their settlement in the South West Pacific (Sahlins 1958, Goldman 1970, Bellwood 1978).

The level of scale developed in Melanesia is found in other areas of the world. If we are interested in how things work for Melanesian groups, we have quite an impressive corpus of material, local and comparative, to work with. And all the points mentioned by Paula are crucial factors to address. However, as mentioned above, relatively little of this is central to the question of why Melanesians independently developed neither chiefs nor states.

\section{CONCLUSIONS}

Ethnographic methods and literature allow us to describe the ways that things like big man systems, Austronesian chiefdoms, ethnicity and kinship work. Do we want anthropology to do more? Or is the discipline, in fact, striving to do less? If we want to answer scientific questions, and Paula's question is of this sort, we need to 'aspire to be a science.' (Romney, 1999: S113). 
Reflecting on his long career, A. Kimball Romney, notes that social anthropology in the 1950 s had the potential to advance scientific knowledge of human behavior. It now appears to him that our subject is very nearly moribund in this sense...The will, the skill, and the modesty required to bring our ideas into the 'empirical arena where each assertion has to be tested by the appropriate 'objective' methodology are lacking.' The issues that came up in the discussion about Guns, Germs, and Steel, in Savage Minds and the ASAO session on hierarchy in Melanesia show that we have to go, not only beyond ethnography, but back to an almost forgotten ethos to breathe some life into a nearly dead project.

All of the examples cited in this paper show that there is a real reluctance to do so. The exchange between Gewertz, Errington, and Patrick in Savage Minds is an especially blatant example of withdrawing from empiricism. No grounds for a real conversation can exist when one party blithely makes up the other's position and then demolishes what is, in fact, their own construction. Something very similar happens in the literature on ethnicity and kinship. How can we understand the latter when these phenomena are treated as products of anthropologists' own imaginations?

As disheartening as this state of affairs may seem to old, and soon to be oldtimers, postmodernism may ultimately prove less of a problem for anthropology than the gap that exists between the eponymous lumpers and splitters of this paper. After all, as Goldblatt says, there really are no grounds for humanists and postmodernists to converse. It is as useless as evolutionary biologists having a fruitful debate with creationists. It is the splitters who pose far more serious problems for us lumpers than the postmodernists.

The anthropologists in the ASAO session who were so unimpressed with Diamond all seem to be humanists. They are experienced ethnographers with a deep understanding of Melanesian political systems; they are looking for evidence of a reality that exists beyond them and welcome evidence-based discussion and debate about their interpretations. They discuss human nature and how their informants think and act. The reluctance to take seriously the geographical, botanical, epidemiological, and technological variables Diamond privileges is more continuous with trends in the history of anthropology than the recent radical flirtation with models imported from literary criticism. It is part of a narrowing of anthropological horizons that has been going on longer than Romney mentioned, in fact, ever since the demise of evolutionism and diffusionism. If a narrowing focus leads to increased precision and understanding, it would serve anthropology well. However, when we find Kapferer 
worried about the assault on the two pillars of our subject, ethnography and culture, just a few years after basic reference books talk about the anthropological triangle of ethnography, context and comparison, the base is, if not gone, at least shaky.

It is sensible for anthropologists to find Diamond annoying. He pays little attention to culture and the work of anthropologists that is relevant to his question. Bodley, on the other hand, provides a perfectly useful alternative to Guns Germs and Steel. However, he is best known for his introductory textbook (Bodley 2005) and work on endangered cultures. I hadn't even heard of his theory of scale until I read about it when I was looking at adopting his text for Victoria University's Anthropology 101 course for 2007. Certainly, no one at the ASAO session mentioned him, nor do they seem inclined to take his position any more seriously than Diamond's. Frankly, it's disheartening. A big question, such as Paula's, just can't be answered unless we are prepared to go beyond ethnography and, once again in Romney's words, 'aspire to become a science'.

\section{REFERENCES}

Banks, M. 1996. Ethnicity: Anthropological Constructions. London, Routledge.

Bellwood, P. 1978. The Polynesians: Prehistory of an Island People. London: Thames and Hudson.

Bodley, J. 1999. 'Socioeconomic Growth, Culture Scale, and Household Well-Being A Test of the Power-Elite Hypothesis', Current Anthropology, 40:595-620.

Bodley, J. 2005. Cultural Anthropology, Tribes, States and the Global System, Fourth Edition. Boston: McGraw Hill.

Brown Glick, P. 1960. 'Chimbu Tribes: Political Organization in the Eastern Highlands of New Guinea', Southwestern Journal of Anthropology, 16: 22-35.

Brown Glick, P. 1990. 'Big man, Past and Present: Model, Person, Hero, Legend', Ethnology, 29: 97-115.

Brumann, C. 1999. 'Writing for Culture: Why a Successful Concept Should Not Be Discarded, Current Anthropology, 40 (Supplement): S1-S27. 
Diamond, J. 1998. Guns, Germs and Steel: A Short History of Everybody for the Last 13,000 Years. London: Vintage.

Diamond, J. 2005. Collapse: How Societies Choose to Fail or Succeed. New York, Penguin.

Durrenberger, G. 1996. 'Ethnography' in Encyclopedia of Cultural Anthropology. New York: Henry Holt and Co.

Errington, F. and Gewertz, D. 2004. Yali's Question: Sugar, Culture, and History. Chicago: University of Chicago Press.

Fortes, M. and Evans-Pritchard, E.E. 1940. African Political Systems. London: Oxford.

Fox, R. 1993. Reproduction and Succession Studies in Anthropology, Law, and Society. New Brunswick: Transaction Publishers.

Fox, R. 1997. Conjectures \& Confrontations: Science, Evolution, Social Concern. New Brunswick: Transaction Publishers.

Franklin, S. 1998. Incontestable Motivations: Reproducing Reproduction: Kinship, Power, and Technological Innovation. Philadelphia: University of Pennsylvania Press: $118-131$.

Gewertz, D. and Errington, F. n.d. 'Pizarro, Millais, Diamond, and Yali: Our Last Waltz.' http://savageminds.org/2005/o9/12/pizarro-millais-diamond-andyali-our-last-waltz/.

Goldblatt, M. 2006. 'Can Humanists Talk to Postmodernists?' ducts.org the Webzine of Personal Stories 17.

Goldman, I. 1970. Ancient Polynesian Society. Chicago: University of Chicago Press.

Kapferer, B. 200o. 'Star wars: About anthropology, culture and globalisation.' The Australian Journal of Anthropology, 22: 174-198.

Levine, H. B. 1999. 'Reconstructing Ethnicity.' J. Royal Anthropological Institute, 52: $165-180$. 
Levine, H. B. 2003. 'Gestational Surrogacy: Nature and Culture in Kinship', Ethnology 42:173-186.

Needham, R. 1971. Re-thinking Kinship and Marriage. London: Routledge.

Peletz, M. 1995. 'Kinship Studies in Late Twentieth-Century Anthropology'. Annual Review of Anthropology 24:343-372.

Ragoné, H. 1994. Surrogate Motherhood: Conception in the Heart. Boulder: Westview.

Ragoné, H. 1996. 'Chasing The Blood Tie: Surrogate Mothers, Adoptive Mothers And Fathers' American Ethnologist 23(2):352-365.

Romney, A. K. 1999. 'Culture Consensus as a Statistical Model' Current Anthropol-

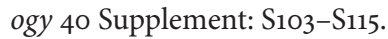

Sahlins, M. 1958. Social stratification in Polynesia. Seattle: University of Washington Press

Sanjek, R. 1996. 'Ethnography' in Encyclopaedia of Social and Cultural Anthropology', v.1: 94-198.

Scaglion, R. 2005. Personal Communication.

Schneider, D. 1968. American Kinship: A Cultural Account. Chicago: University of Chicago Press.

Strathern, M. 1994. 'New Knowledge for Old? Reflections Following Fox's Reproduction and Succession' Social Anthropology 2(3): 263-279. 